\title{
Asbestos exposure during home renovation in New South Wales
}

\section{Eun-Kee Park \\ MASc, PhD Associate Professor \\ Deborah H Yates MB BChir, MD, FRCP Thoracic Physician, ${ }^{2}$ and Conjoint Associate \\ Rebecca A Hyland \\ Research Assistant \\ Anthony R Johnson \\ MB BS, MOHS, FRACP, \\ Thoracic Physician \\ 1 Department of Medical Humanities and Social Medicine, College of Medicine, Kosin University Busan, Korea. \\ 2 Department of Thoracic Medicine St Vincent's Hospital, Sydney, NSW. \\ 3 University of New South Wales, \\ Sydney, NSW. \\ 4 Department of Thoracic Medicine Liverpool Hospital, Sydney, NSW. \\ deborahy88@ hotmail.com}

MJA 2013; 199: 410-413 doi: 10.5694/mjal2.11802

\section{1} sbestos inhalation is established beyond doubt as the cause of the fatal cancer malignant mesothelioma (MM). Recently, there has been an epidemic of asbestos-related diseases in several westernised nations, resulting from past occupational exposure. ${ }^{1,2}$ Although estimates suggest that more than 125 million people are exposed to asbestos in occupational settings, ${ }^{3}$ the number of people non-occupationally exposed is not known.

Asbestos is a generic term for a number of different fibrous silicates, which vary in their potency for causing malignancy and include amphiboles (crocidolite or blue asbestos) and amosite (brown asbestos), and serpentine forms such as chrysotile (white asbestos). Health risks associated with amphibole exposure are much greater than those with chrysotile. ${ }^{4}$ However, all types are currently classified as carcinogenic, and no threshold for exposure has been identified for chrysotile in recent $\mathrm{WHO}$ reports, ${ }^{5}$ although this issue is still controversial. $^{6}$

Asbestos use has been banned in many industrialised countries since the 1970s, but asbestos-containing materials are still found in many buildings in Australia, including domestic residences. ${ }^{7,8}$ The housing boom after World War II required new types of construction materials to compensate for a shortage of bricks, ${ }^{9}$ especially in New South Wales. Thus, asbestos cement sheeting, commonly known as "fibro", was intensively produced and used during this period. Australian fibro sheeting contained amphibole as well as chrysotile asbestos until the mid 1980s. ${ }^{7}$

The United States Centers for Disease Control and Prevention (CDC) have warned that asbestos-containing materials can be disturbed during maintenance, renovation or demolition activities, and that precautions should be used to minimise asbestos exposure. ${ }^{10}$ Australia has the highest per-capita rate of asbestos diseases in the world, and rates of MM continue

\section{Abstract}

Objective: Asbestos exposure is causally associated with the development of malignant mesothelioma ( $\mathrm{MM}$ ), which is increasingly being reported after exposure to asbestos fibro sheeting in Australia. In this study, we investigate self-reported non-occupational asbestos exposure during home renovation in New South Wales.

Design and setting: Cross-sectional mailed questionnaire examining renovation activity, tasks undertaken during renovation and self-reported exposure to asbestos among respondents and their family members in NSW between January and June 2008.

Participants: 10000 adults aged 18-99 years, randomly selected from the NSW electoral roll. We received 3612 responses, while 365 questionnaires did not reach addressees, giving an overall response rate of $37.5 \%$.

Main outcome measures: Differences in self-reported asbestos exposure between do-it-yourself (DIY) and non-DIY renovators.

Results: 1597 participants (44.2\%) had renovated their home and among these, 858 participants (53.7\%) self-reported as DIY renovators. Of these, 527 (61.4\%) reported asbestos exposure during home renovations, 337 (39.3\%) reported that their partner had been exposed to asbestos during renovations, and $196(22.8 \%)$ reported that their children had been exposed. More than $20 \%$ of renovators planned to further renovate their current homes within the next 5 years.

Conclusions: Self-reported asbestos exposure during home renovation is common. This preventable exposure could place adults and children at risk of MM many years into the future. Although such exposure is self-reported and ideally should be verified, this study identifies a potentially important problem in NSW.

to climb. ${ }^{11,12} \mathrm{MM}$ secondary to exposure to asbestos-containing materials is an emerging public health problem. ${ }^{13-17}$ Recently, there has been concern that exposure from disturbance of building products, including through do-it-yourself (DIY) home renovation activities, accounts for an increasing proportion of deaths from MM. ${ }^{16,17}$ The proportion of cases of MM in Western Australia attributed to home renovation has increased markedly in both men and women over the past 10 years. ${ }^{17}$ Home renovation is a popular activity in Australia, and asbestos-containing materials may be a source of exposure to householders if respirable asbestos dust is released.

The Federal Government recently approved a national strategic plan to improve asbestos identification and management and remove all asbestos-containing materials from government and commercial buildings by $2030 .^{18}$ This includes examination of the feasibility of removal of asbestos from residential properties. Over 820000 dwellings in Australia (about
$15 \%$ of dwellings constructed before 1987) are reported to have asbestoscontaining materials or fibro as a main construction material, but the exact number of homes containing asbestos products is not known.

No studies have assessed the frequency of home renovation in NSW and the number of people taking precautions against asbestos exposure during these activities. In this study, we aimed to describe the proportion of individuals who reported asbestos exposure during both DIY and nonDIY home renovations and their types of exposure.

\section{Methods}

This study was conducted between January and June 2008 in NSW, and approved by the NSW Electoral Commission and the Prince of Wales Hospital's Human Research Ethics Committee. A structured questionnaire was mailed to 10000 adults randomly selected from the NSW electoral roll. This was designed to 
1 Participant characteristics and self-reported exposure to asbestos

\begin{tabular}{lccccc} 
& Total & $\begin{array}{c}\text { Never } \\
\text { renovated }\end{array}$ & $\begin{array}{c}\text { Renovated, } \\
\text { DIY }\end{array}$ & $\begin{array}{c}\text { Renovated, } \\
\text { not DIY }\end{array}$ & $P$ \\
\hline All respondents & 3612 & 2015 & 858 & 739 & \\
& $(100 \% *)$ & $(55.8 \% *)$ & $(23.8 \% *)$ & $(20.5 \% *)$ & \\
Characteristics & & & & & \\
Mean age in years & 51.3 & 49.8 & 52.5 & 53.9 & $<0.001$ \\
(SD) & $(13.4)$ & $(14.0)$ & $(12.5)$ & $(12.2)$ & \\
Male & 1609 & 848 & 490 & 271 & $<0.05$ \\
& $(44.5 \%)$ & $(42.1 \%)$ & $(57.1 \%)$ & $(36.7 \%)$ & \\
Experienced occupational & 439 & 157 & 225 & 57 & $<0.05$ \\
asbestos exposure & $(12.2 \%)$ & $(7.8 \%)$ & $(26.2 \%)$ & $(7.7 \%)$ & \\
Experienced asbestos & 547 & $n a$ & 527 & 20 & $<0.001$ \\
exposure during renovation ${ }^{\dagger}$ & $(15.1 \%)$ & & $\left.(61.4 \%)^{\ddagger}\right)$ & $\left.(2.7 \%)^{\ddagger}\right)$ & \\
Current home contains & 584 & 188 & 252 & 144 & $<0.01$ \\
asbestos & $(16.2 \%)$ & $(9.3 \%)$ & $(29.4 \%)$ & $(19.5 \%)$ & \\
Planning renovations in & 515 & 190 & 215 & 110 & $<0.05$ \\
next 5 years & $(14.3 \%)$ & $(9.4 \%)$ & $(25.1 \%)$ & $(14.9 \%)$ & \\
Planning renovations and & 139 & 36 & 76 & 27 & $<0.05$ \\
home contains asbestos & $(3.8 \%)$ & $(1.8 \%)$ & $(8.9 \%)$ & $(3.7 \%)$ & \\
\hline
\end{tabular}

DIY $=$ do-it-yourself. na $=$ not applicable. $*$ Percentage row totals calculated for first row only. $\dagger$ Including partner or children exposed to asbestos. $¥$ Associations between variables were evaluated by analysis of variance for arithmetic means and $\chi^{2}$ test for proportions.

measure renovation activity, tasks undertaken and family members exposed to asbestos. Each participant was asked to report on up to three episodes of renovation. Up to two follow-up questionnaires were sent to non-responders. The questionnaire is available on request.

\section{Statistical analysis}

Data were entered into a Microsoft Excel database and analysed using SPSS version 13.0 (SPSS Inc). Values are reported as arithmetic means (SDs). Associations between variables were evaluated by analysis of variance for arithmetic means and $\chi^{2}$ test for proportions. $P<0.05$ was considered statistically significant.

\section{Results}

A total of 3612 responses were received, giving an overall response rate of $37.5 \%$ (Box 1 and Box 2). There were 363 incorrect addresses and two people were reported as deceased; 9635 people received questionnaires. Of the 3212 participants who reported their age, the mean age was 51.3 years (SD, 13.4 years). There were 1955 women and 1610 men, and 47 participants did not report their sex.

Of the 1597 respondents (44.2\%) who reported having home renovations, 858 participants (53.7\%) were DIY renovators, and 739 (46.3\%) were non-DIY renovators. Most of the DIY renovators $(527 ; 61.4 \%)$ reported having had asbestos exposure, and 20 respondents $(2.7 \%)$ in the non-DIY group also reported having exposure. DIY renovators were more likely to be male (491 respondents; 57.2\%) than non-DIY renovators $(P<0.05)$.

In answer to the question "does your current home contain asbestos?", 584 respondents (16.2\%) reported that it did, and 1020 respondents (28.2\%) did not know. Of the respondents who reported that their current homes contained asbestos, 252 (43.2\%) were DIY renovators. Of the total 858 DIY renovators, 337 respondents $(39.3 \%)$ reported that their partner had been exposed to asbestos during renovations, and 196 participants $(22.8 \%)$ reported that their children had been exposed as well as their partner. Non-DIY renovators were less likely to report exposure to asbestos or that their partner or children had been exposed to asbestos than DIY renovators $(P<0.05)$. A small proportion of the total group (515 respondents; 14.3\%) had plans to renovate their homes in the next 5 years. These plans were more common among the DIY renovators (215 respondents; $25.1 \%$ ) than non-DIY renovators (110; $14.9 \%$ ) and those who had never renovated (190; $9.4 \% ; P<0.05)$. A small proportion of the total group were living in a house containing asbestos and planning renovations $(139 ; 3.8 \%)$. Once more, respondents differed in their renovation plans for homes containing asbestos, with more DIY renovators (76; 8.9\%) planning to renovate than non-DIY renovators $(27 ; 3.7 \%)$ and those who had never renovated (36; $1.8 \% ; P<0.05)$.

Among the DIY renovators, selfreported exposure to asbestos cement fibro sheeting was the most common type of exposure (508/527; 96.4\%), followed by exposure to asbestos insulation $(73 / 527 ; 13.9 \%$ ) and to other materials, such as those used in bathroom, roofing and fencing work (48/527; 9.1\%) (Box 2).

\section{Discussion}

Our study provides the first detailed survey of self-reported exposure to asbestos in home renovation in NSW. We found that reported DIY asbestos exposure was common. As would be expected, women were less likely to report DIY asbestos exposure than men. During home renovations, $22.8 \%$ reported their partner and children had also been exposed to asbestos. Only $12.0 \%$ of the DIY renovators reported using respiratory protection regularly, while $28.4 \%$ used this occasionally. About $14 \%$ of respondents planned to renovate within the next 5 years.

Ideally, our study would have measured actual rather than reported exposure, but this was not possible in this epidemiological survey. Assessing past exposures is difficult. In the occupational context, many approaches exist: detailed occupational histories, job exposure matrices, expert assessments and exposure databases, among others. However, it is acknowledged that the variability between studies is significant and that overall the validity of exposure estimation methods is poor. ${ }^{19}$ Validity is likely to be even more questionable for non-occupational exposures, although this issue deserves more research. It is likely that overall exposures from reported asbestos contact will be low. Measurement of airborne asbestos fibre levels during renovation of asbestos cement-clad buildings have shown levels between 0.1 and 0.2 fibres per $\mathrm{mL}$, reducing when appropriate precautions are used, ${ }^{20}$ but few Australian data are available. ${ }^{7}$ 


\section{Characteristics of 858 do-it-yourself (DIY) home renovators}

\begin{tabular}{|c|c|c|c|}
\hline \multirow[b]{2}{*}{ Characteristic } & \multicolumn{3}{|c|}{ Episode of renovations* } \\
\hline & 1 & 2 & 3 \\
\hline \multicolumn{4}{|l|}{ Exposure type } \\
\hline Contact with asbestos fibro sheeting & \multicolumn{3}{|c|}{$508(59.2 \%)$} \\
\hline Contact with asbestos insulation & \multicolumn{3}{|c|}{$73(8.5 \%)$} \\
\hline Contact with asbestos in other materials & \multicolumn{3}{|c|}{$48(5.6 \%)$} \\
\hline \multicolumn{4}{|l|}{ Task-related exposure } \\
\hline Cutting asbestos building materials & $287(33.4 \%)$ & $131(15.3 \%)$ & $57(6.6 \%)$ \\
\hline Drilling asbestos building materials & $215(25.1 \%)$ & $110(12.8 \%)$ & $43(5.0 \%)$ \\
\hline Sanding asbestos building materials & $99(11.5 \%)$ & $49(5.7 \%)$ & $15(1.7 \%)$ \\
\hline \multicolumn{4}{|c|}{ Tools used for cutting asbestos building materials } \\
\hline Hand and power tools & $138(16.1 \%)$ & $58(6.8 \%)$ & $25(2.9 \%)$ \\
\hline Hand tool & $131(15.3 \%)$ & $62(7.2 \%)$ & $26(3.0 \%)$ \\
\hline Power tool & $25(2.9 \%)$ & $13(1.5 \%)$ & $7(0.8 \%)$ \\
\hline \multicolumn{4}{|l|}{ Respiratory protection among all DIY renovators } \\
\hline Always wore respiratory protection & \multicolumn{3}{|c|}{$103(12.0 \%)$} \\
\hline Sometimes wore respiratory protection & \multicolumn{3}{|c|}{$244(28.4 \%)$} \\
\hline Never wore respiratory protection & \multicolumn{3}{|c|}{$271(31.6 \%)$} \\
\hline \multicolumn{4}{|l|}{ Cleaned up asbestos products } \\
\hline Yes & $401(46.7 \%)$ & $179(20.9 \%)$ & $69(8.0 \%)$ \\
\hline No or do not know & $135(15.7 \%)$ & וו1 (12.9\%) & $54(6.3 \%)$ \\
\hline \multicolumn{4}{|c|}{ Undertook demolition and removal of asbestos products } \\
\hline Yes & $309(36.0 \%)$ & $140(16.3 \%)$ & $63(7.3 \%)$ \\
\hline No or do not know & $227(26.5 \%)$ & $149(17.4 \%)$ & $60(7.0 \%)$ \\
\hline
\end{tabular}

* Survey participants were asked to report on up to three episodes of renovation.

The exact risk at low levels of exposure (particularly with mixed types of fibres) has not been quantified.

One limitation of our study was the relatively low response rate. Although we designed the study to allow adequate power, and contacted nonresponders with reminders, the participation rate was only $37.5 \%$. However, this response rate is comparable to that of other studies, ${ }^{21}$ and included the largest number of respondents yet surveyed about nonoccupational exposure to asbestos in Australia. We have no reason to assume that responders were more likely to have been exposed to asbestos or to live in homes containing asbestos than non-responders. Some aspects of the survey returns suggest that our results are representative of the NSW population; for example, similar smoking rates to those reported elsewhere, ${ }^{22}$ and the higher rate of DIY activity in men. However, our participants were younger than usual NSW residents, ${ }^{23}$ possibly reflecting a greater interest in asbestos hazards among younger people. Declining response rates in epidemiological studies are a recognised problem, ${ }^{24,25}$ and are affected by questionnaire design and mailing strategies. ${ }^{26}$ Our questionnaire design took into account the current available information on asbestos exposures in $\mathrm{NSW},{ }^{27}$ but is the first such questionnaire to be trialled in this population.

The issue of the role of low-dose exposure in the pathogenesis of MM remains controversial, and is outside the scope of this report. Current unresolved questions include the magnitude of the risk with low-dose exposure, contamination of chrysotile with amphibole asbestos, and whether a threshold level exists below which carcinogenesis does not occur. ${ }^{4,6,14-16}$ Compared with occupational exposure, domestic exposure to asbestos is likely to be $\operatorname{low}^{28,29}$ and also to be underestimated, as asbestos can be difficult to identify - knowledge about the frequency with which it is used is generally low even in construction workers who would be expected to be aware of these hazards. ${ }^{8}$ To our knowledge, an assessment of the awareness of asbestos in domestic dwellings and accuracy of people's perception of any potential hazard has not been reported.

This study documents significant potential exposure to asbestos during
DIY home renovation in NSW. Selfreported asbestos exposure during DIY renovations is common, as is reported exposure of family members, and even basic precautions regarding protection against asbestos inhalation are not used in many DIY renovations. Although recommendations have been made for asbestos removal in the commercial sector, active steps also need to be taken to prevent future possible disease in the residential sector as well. Whether exposure during home renovation will result in disease in the future remains to be seen; however, this entirely preventable exposure needs to be addressed.

Acknowledgements: We thank the study responders and also the Workers' Compensation Dust Diseases Board for its initial support for this study. The later stages of the study including its reporting were unfunded and are entirely the work of the investigators. We would also like to thank Guy Marks for his helpful review of the manuscript.

Competing interests: No relevant disclosures.

Received 12 Dec 2012, accepted 25 Jun 2013.

1 Rushton L, Hutchings SJ, Fortunato L, et al. Occupational cancer burden in Great Britain. Br J Cancer 2012; 107 Suppl 1: S3-S7.

2 Robinson BW, Musk AW, Lake RA. Malignant mesothelioma. Lancet 2005; 366: 397-408.

3 World Health Organization. Elimination of asbestos-related diseases. Geneva: WHO, 2006. http://whqlibdoc.who.int/hq/2006/WHO_SDE_ OEH_06.03_eng.pdf (accessed Nov 2012).

4 Hodgson JT, Darnton A. The quantitative risks of mesothelioma and lung cancer in relation to asbestos exposure. Ann Occup Hyg 2000; 44 : 565-601.

5 International Agency for Research on Cancer. Asbestos (chrysotile, amosite, crocidolite, tremolite, actinolite and anthophyllite). IARC monographs volume 100C. 2012. http:// monographs.iarc.fr/ENG/Monographs/vol100C/ monol00C-11.pdf (accessed Nov 2012).

6 Bernstein D, Dunnigan J, Hesterberg T, et al. Health risk of chrysotile revisited. Crit Rev Toxicol 2013; 43: 154-183.

7 Australian Safety and Compensation Council. Asbestos management and control: a review of national and international literature. Canberra: Commonwealth of Australia, 2008.

8 Australian Capital Territory Government. ACT asbestos management review 2010. Canberra: ACT Government, 2010. http://www.cmd.act. gov.au/_data/assets/pdf_file/0011/235991/ asbestosreview.pdf (accessed Jun 2013).

9 Boyle MJ. An analysis of mesothelioma cases from the Australian asbestos cement manufacturing industry [MOHS thesis]. Sydney: University of Sydney, 1994.

10 Centers for Disease Control and Prevention (CDC). Malignant mesothelioma mortality United States, 1999-2005. MMWR Morb Mortal Wkly Rep 2009; 58: 393-396.

11 Australian Mesothelioma Registry. Mesothelioma in Australia 2011. 1st Annual Report. Sydney: AMR, 2011. http://www.mesothelioma-australia.com/ media/10599/amr\%20report\%20final\%2012\% 20september\%202012.pdf (accessed Nov 2012).

12 Hyland RA, Ware S, Johnson AR, Yates DH. Incidence trends and gender differences in malignant mesothelioma in New South Wales, Australia. Scand J Work Environ Health 2007; 33: 286-292. 
13 Landrigan PJ. The third wave of asbestos disease: exposure to asbestos in place. Public health control. Introduction. Ann N Y Acad Sci 1991; 643: $\mathrm{xV}$-xvi.

14 Bourdès V, Boffetta P, Pisani P. Environmental exposure to asbestos and risk of pleural mesothelioma: review and meta-analysis. Eur J Epidemiol 2000; 16: 411-417.

15 Magnani C, Dalmasso P, Biggeri A, et al. Increased risk of malignant mesothelioma of the pleura after residential or domestic exposure to asbestos: a case-control study in Casale Monferrato, Italy. Environ Health Perspect 2001; 109: 915-919.

16 Rake C, Gilham C, Hatch J, et al. Occupational, domestic and environmental mesothelioma risks in the British population: a case-control study. Br J Cancer 2009; 100: 1175-1183.

17 Olsen NJ, Franklin PJ, Reid A, et al. Increasing incidence of malignant mesothelioma after exposure to asbestos during home maintenance and renovation. Med J Aust 2011; 195: 271-274.

18 Australian Government Department of Education, Employment and Workplace Relations. Asbestos Management Review report June 2012. Canberra: DEEWR, 2012. http://www. deewr.gov.au/WorkplaceRelations/Policies/
AMR/Documents/Asbestos ManagementReview ReportJune2012.pdf (accessed Nov 2012).

19 Teschke K, Olshan AF, Daniels JL, et al. Occupational exposure assessment in casecontrol studies: opportunities for improvement. Occup Environ Med 2002; 59: 575-594.

20 Brown SK. Asbestos exposure during renovation and demolition of asbestos-cement clad buildings. Am Ind Hyg Assoc J 1987; 48: 478-486.

21 Howat P, Jalleh G, Lin C, et al. Residential exposure to asbestos: implications for public health. Proceedings of the 39th Annual Conference of the Public Health Association of Australia; 2009 Sep 28-30; Canberra, Australia.

22 Centre for Epidemiology and research. 2010 Report on Adult Health from the New South Wales Population Health Survey. Sydney: NSW Department of Health, 2011.

23 New South Wales Government Department of Planning. New South Wales state and regional population projections, 2006-2036. 2008 release. Sydney: DoP, 2008. http://www. planning.nsw.gov.au/LinkClick.aspx?fileticket= NsOVOcBKuYc\%3d\&tabid=124\&language =enUS (accessed May 2012).

24 Morton LM, Cahill J, Hartge P. Reporting participation in epidemiologic studies: a survey of practice. Am J Epidemiol 2006; 163: 197-203.
25 Galea S, Tracy M. Participation rates in epidemiologic studies. Ann Epidemiol 2007; 17: 643-653.

26 Eaker S, Bergström R, Bergström A, et al. Response rate to mailed epidemiologic questionnaires: a population-based randomized trial of variations in design and mailing routines. Am J Epidemiol 1998; 147: 74-82.

27 Hyland RA, Yates DH, Benke G, et al.

Occupational exposure to asbestos in New South Wales, Australia (1970-1989): development of an asbestos task exposure matrix. Occup Environ Med 2010; 67: 201-206.

28 Environmental Health Standing Committee (enHealth). Management of asbestos in the nonoccupational environment. Canberra: Australian Government, 2005. www.nphp.gov.au/enhealth/ council/pubs/pdf/asbestos.pdf (accessed Jun 2013).

29 Environmental Health Standing Committee (enHealth). Asbestos: a guide for householders and the general public. Canberra: Australian Health Protection Principle Committee, 2013. http://www.health.gov.au/internet/main/ publishing.nsf/Content/ohp-enhealth-asbestosmay2012.htm (accessed Jun 2013). 